\title{
Food portions and consumer vulnerability: qualitative insights from older consumers
}

Nicholas Ford $^{\text {a*}}{ }^{\text {, Paul Trott }}{ }^{\text {a }}$, Christopher Simms ${ }^{\text {a }}$

*Corresponding author: nicholas.ford@ port.ac.uk, Tel: +44 2392844141

${ }^{a}$ University of Portsmouth, Portsmouth Business School, Richmond Building, Portsmouth, PO3 1DE, United Kingdom

\section{Purpose}

The purpose of this paper is to explore older people's food consumption experiences. Specifically, the paper seeks to provide understanding on the influence of food intake on consumer vulnerability and how this manifests within people's lives.

\section{Design/methodology/approach}

The study adopts an interpretive, exploratory approach, utilising in-depth interviews with 20 older consumers in the United Kingdom. Thematic analysis is conducted, establishing patterns and contradictions with the data.

\section{Findings}

The findings demonstrate how biological, psychological, and social age-related changes can contribute to reduced food intake in later life. The loss of control over one's consumption experiences as a result of inappropriate portion sizes acts as a source of both immediate and future vulnerability. Resultant food wastage can serve as an immediate reminder of negative associates with ageing, while the accumulative effect of sustained under-consumption contributing to increased frailty. As a result, consumer vulnerability can pervade other contexts of an individual's life.

\section{Practical implications}

The research reveals opportunities for firms to utilise packaging development to reduce experiences of consumer vulnerability through reduced apportionment of packaged food products. However, this needs to be considered within a multi-demographic marketplace. 


\section{Originality/value}

This paper contributes to literature by providing a unique lens with which to understand consumer vulnerability. The findings offer a developmental perspective on the experience of consumer vulnerability, revealing the stages of proximate, immediate, intermediate and ultimate vulnerability. This perspective has the potential to offer more detailed, nuanced insights into vulnerability in other contexts beyond food consumption.

\section{Key words:}

Food portions; packaging; ageing; consumer vulnerability. 


\section{Food portions and consumer vulnerability: qualitative insights from older consumers}

\section{Introduction}

The purpose of this paper is to explore how ageing affects food consumption practices. Currently, there are an estimated 962 million people aged 60 or over globally, with this figure estimated to reach 2.1 billion by 2050 , forming more than $21 \%$ of the world population (United Nations, 2017). According to Soenen and Chapman (2013), ideal body weight for maximum life expectancy increases with advancing age. While public health debates call for greater consumer restraint in light of the growing obesity crisis (Cornil and Chandon, 2016), the opposite is true for those older people who require increased food consumption. Despite this, food intake is found to decrease for many during later life, with subsequent weight loss and undernutrition prevalent among many older people (Koehler, 1994; Sjögren et al., 1994; Briefel, et al., 1995).

Reduced food consumption and decreases in body fat and body weight among older people is characterised as the 'anorexia of ageing' (Morley, 1997; Hays and Roberts, 2006; Benelam, 2009), a progressive disorder, estimated to affect $25 \%$ of older men and $30 \%$ of older women (MacIntosh et al., 2000). Despite this prevalence, Landi et al. (2016) describe how problems related to food intake and nutritional status are seldom attended to in clinical practice, often leading to increased frailty and vulnerability (MacIntosh et al., 2000; Marshall et al., 2001). Understanding the effects of ageing on food consumption is therefore of significance to many packaged food firms.

Despite this, research into food volume consumption among older adults is relatively limited within the Marketing literature. Prior Gerontological studies have focussed on biological agerelated changes that lead to declines in appetite during later life (e.g. Morley, 1997; MacIntosh et al., 2000; Malafarina et al., 2013), with psychological and social factors 
receiving less attention (de Boer et al., 2013). Using data gathered from twenty in-depth interviews with older consumers, this paper builds upon those insights by considering in greater depth how the effects of reduced food intake manifest in the lives of older people.

Based on the above, the following research questions are considered: How does ageing affect food consumption practices? How does reduced food intake contribute to vulnerability among older people?

Using a multidimensional perspective of ageing, we argue that biological, psychological, and social age-related changes can influence food consumption practices in a variety of ways, including contributing to reduced food intake in later life. This can render the portion sizes of a variety packaged foods inappropriate for many older people, contributing to consumer vulnerability where older people experience a loss of control over their consumption experiences (Baker et al., 2005). Consumer vulnerability elicits feelings powerlessness over one's consumption experiences, placing greater dependence on external sources to create fairness in the marketplace (Adkins and Jae, 2010; Baker et al., 2005; Commuri and Ekici, 2008). In this case, dependence is placed on food marketers to provide products which facilitate adequate food consumption in later life.

This paper extends our understanding of consumer vulnerability by exploring the concept within a new context among a significant yet relatively underexplored group of consumers (Ford et al., 2016; Roy and Sanyal, 2017). Specifically, inappropriate portion sizes are identified as a potential source of immediate vulnerability, where older people are unable to achieve their consumption goals and food waste acts as an unwanted reminder of negative aspects of the ageing process. Furthermore, unsuitable portion sizes can also act as a contributor to future vulnerability. The accumulative effect of sustained periods of insufficient food consumption may contribute to increased frailty, leading to greater incidents 
of vulnerability in a variety of contexts. These findings provide a developmental perspective on experiences of consumer vulnerability yet to be fully captured within other studies.

The paper is organized as follows: firstly, studies of ageing are considered in relation to the consumer vulnerability and food portions Marketing literature. Secondly the methodology is detailed. Thirdly, our findings are presented and analysed. Finally, conclusions are drawn, with reference to theoretical contributions, managerial implications, and limitations of the study and suggested future research directions.

\section{Literature review}

Ageing and food intake

Ageing is understood within the Marketing literature to be a heterogeneous, multidimensional process consisting of biological, psychological and social changes (Leventhal, 1997; Szmigin and Carrigan, 2010; Moschis et al., 2011). Biological ageing refers to changes to an individual's cells and tissues which impact on physiology. Distinction is made between primary biological ageing (universal changes occurring with age independent of stress and disease) and secondary biological ageing (changes involving interactions of primary ageing processes with environmental influences and disease processes) (Masoro, 2006).

Psychological ageing sees cognitive changes that affect a person's attitudes and opinions, as well as their ability to think and reason. Social ageing consists of changes to life roles and social relationships that often follow significant events such as retirement, becoming a grandparent or suffering bereavement (Ahmad, 2002; Bond et al., 2007). Numerous studies have demonstrated how these different dimensions of ageing can influence marketplace 
interactions (e.g. McKay-Nesbitt et al., 2011; Kuppelwieser and Sarstedt, 2014; Amatulli et al., 2015).

With regards to food consumption, a variety of biological changes as people age are identified as contributing to reductions in food intake. For example, Martone et al. (2013) describe declines in the activities of specific brain areas contributing towards reductions in food intake. Such activities include hypothalamus, where declines inhibit an individual's responses to hunger hormones such as ghrelin and cholecystokinin, thus contributing to decreased hunger and unexpected weight loss in later life (Horwitz et al., 2002; Conte et al., 2009; Morley et al., 2009). Other studies highlight changes in motility and intestine transit contributing to feelings of satiation following food consumption (e.g. Clarkston et al., 1997; Malafarina et al., 2013). In addition to physiopathological factors, sensory changes are also found to contribute to the pathogenesis of the anorexia of ageing. For example, reductions in abilities to taste and smell resulting in a loss of pleasure derived from eating are highlighted as contributing factors (e.g. Popper and Kroll, 2003; Dean et al., 2009; Doty and Kamath, 2014). As a result of these biological changes, reduced food intake among older people has been linked to the development and progression of chronic diseases including osteoporosis, cardiovascular disease, diabetes mellitus and cancer (MacIntosh et al., 2000; Marshall et al., 2001).

While comparatively scarce, research exploring the impact of psychological and social ageing on reduced food intake suggests non-biological factors may also significantly contribute to the anorexia of ageing. For example, de Boer et al. (2013, pp. 324) highlight social factors including widowhood and subsequent feelings of social isolation due to living alone as contributing to reduced food intake: "changes in social environment of widowed participants altered the social meaning and daily routines of eating which resulted in negative feelings associated with eating and a subsequent reduced food intake". Other social factors 
contributing to the anorexia of ageing may also include changes to an individual's environment. For example, time spent in hospitals or nursing homes is found to disrupt personal eating schedules, potentially leading to sustained decreases in appetite (Donini et al., 2003; Mathey et al., 2001). As a result of these social changes, older people may develop negative associations with ageing which in turn contribute to psychological changes that further exacerbate the anorexia of ageing. Such psychological changes may include experiences of depression which has been linked with weight loss among older people (DiPietro et al., 1992) as depressive moods and negative emotions have been found to lead to decreases in appetite (Macht et al., 2002). As such, decreased food intake as a result of biological and social changes is reinforced by psychological changes in response to these altered circumstances. This leads to a vicious cycle of factors potentially contributing to the onset of the anorexia of ageing. Therefore, it is necessary to consider how product features such as portion sizes may influence food intake.

\section{Portion size and food consumption}

A stream of literature has emerged exploring the effects of food portion size and container composition on consumption. Much of this research focuses on encouraging responsible consumption in light of growing obesity rates. For example, Wansink (1996) highlights the 'supersizing' of products featuring increased portions and packaging as a prime driver of overconsumption. Several studies posit that increases in portion size lead to increased consumption (e.g. Wansink, 2004; Chandon and Wansink, 2011; Zlatevska et al., 2014). Using a meta-analytic review Zlatevska et al. (2014) reveal that when portion sizes are doubled, food consumption increases by $35 \%$ on average across a range of food types and contexts. In their exploration of 'tempting treats' such as chocolates, Do Vale et al. (2008) 
reveal how smaller portions can lead to increased food consumption, as consumers view smaller quantities of tempting products as 'acceptable' self-regulatory tools. Conversely, larger portions are perceived as 'unacceptable', hence consumers engage in greater deliberation, often leading to comparatively modest food intake. Taken together, these studies suggest that through alterations to container composition and portion size, food marketers may be able to influence consumers towards more appropriate levels of consumption. There are commercial risks, however, to product downsizing as consumers may perceive these changes as being deceitful and offering lower value (Vermeer et al., 2010). While providing critical insights and implications for reducing overconsumption, the majority of these studies overlook the consumption habits of older people.

In their exploration of post-stroke depression among older people, Laidlaw et al. (2002) describe how increases in food portions can contribute to decreased food intake. Referencing the war-time 'waste-not want-not' attitude of their participants, Laidlaw et al. (2002) highlight a 'vicious cycle' where increased portion sizes lead to greater food wastage, resulting in feelings of shame and the tarnishing of morale. These feelings further exacerbate reductions in appetite. Rather than increasing portion sizes, the authors describe reductions in portion and plate sizes as a more effective form of intervention as this leaves the impression of having finished a meal, resulting in a reduction in anxiety and an increase in weight gain due to the increased sense of mastery. This suggests that decreased portion sizes may encourage greater food intake among older people. However, due to the lack of attention afforded to older people's food consumption practices, studies purporting this view are limited, meaning further exploration is required. Furthermore, while studies from the Nutritional and Gerontological literature highlight how reduced food intake may contribute to increased frailty and vulnerability in later life (e.g. MacIntosh et al., 2000; Marshall et al., 2001; Martone et al., 2013), details of how this vulnerability manifests in people's lives and 
affects consumer behaviour is limited. As such, examining older people's food consumption practices with respect to conceptualisations of consumer vulnerability may provide new insights.

\section{Food portions and consumer vulnerability}

Situations where food products suited to the needs of older consumers are unavailable may lead to experiences befitting of Baker et al. 's (2005, p. 134) conceptualisation of consumer vulnerability wherein the consumer is "unable to accomplish his or her goals in a consumption situation because of being powerless, out of control, and so forth". This loss of control creates a situational state of vulnerability where consumers place greater dependence on external factors, such as marketers or the state, to create fairness in the marketplace (Baker et al., 2005; Commuri and Ekici, 2008). As such, consumer vulnerability entails "a state of powerlessness, manifesting when individual characteristics and fluctuating consumer states combine with structural and socioenvironmental elements to produce conditions where marketplace imbalances or harm may occur as a result of consuming [products]" (Adkins and Jae 2010, p. 95). According to a situational stated-based view of vulnerability, experiences of consumer vulnerability are transient, meaning they are likely to be confined to the specific marketplace interaction where they arise. Vulnerability is considered, therefore, to be impermanent. Commuri and Ekici (2008) extend this view, suggesting that some groups of consumers may be more susceptible to experiences of vulnerability. This is characterised as a class-based view. The authors advocate for an integrative view of vulnerability, recognising that these experiences may be transient for many people, while others may be susceptible to more frequent and enduring vulnerability. 
As Shultz II and Holbrook (2009) describe, a paradoxical relationship exists where Marketing can both reduce and contribute to consumer vulnerability. Reductions in food intake may render the portion sizes of packaged foods inappropriate for some older people, creating an imbalance between consumption goals and marketplace offerings. This loss of control over food consumption experiences may negatively affect an individual's self-concept. Prior studies have highlighted the importance of food consumption experiences to older people. For example, using semi-structured interviews with older Scottish people, McKie (1999) discovered that in many cases food consumption was directly linked to the maintenance of independence in later life. She also found that food shopping and meal times were used as strategies for avoiding social isolation. The significance of commensality (the practice of eating together) among older people has been suggested across a variety of contexts (e.g. Quandt et al., 2000; Paquet et al., 2008; Dean et al., 2009). In his exploration of older people's use of domestic spaces, Percival (2002) describes how the organisation of eating routines is clearly fundamental in the management and use of domestic home spaces. This highlights the importance of meal times to older people, whether they are eating alone or with others. Given the significance of food consumption to life satisfaction (Dean et al., 2009), difficulties in achieving food-related goals may, therefore, act a source of vulnerability for some older people.

Although no demographic group is predisposed to experience vulnerability in all contexts, the process of ageing may increase the susceptibility of older people to experience consumer vulnerability in a variety of marketplace exchanges (Duizer et al., 2009). Several studies have explored older people's experiences of consumer vulnerability. For example, considerable attention has been afforded to older people's susceptibility to experience fraud through unethical sales or telemarketing activities (e.g. Lee and Soberon-Ferrer, 1997; Lee and Geistfeld, 1999; Langenderfer and Shimp, 2001; Alves and Wilson, 2008). Very few studies, 
however, have explored older consumers' experiences of vulnerability when interacting with food products. In their study into older consumers' experiences with fast-moving consumer goods product packaging, Ford et al. (2016) uncovered positive coping mechanisms employed by older people when encountering difficulties opening products. The use of specialist tools as well as other more rudimentary 'home-made' opening solutions are also described in other studies (e.g. Yoxall et al., 2010; Sudbury-Riley, 2014). While these positive coping mechanisms demonstrate high levels of mastery among some older people (Aldwin, 1991; Ben-Zur, 2002; Blanchard-Fields et al., 2007), methods for overcoming the potential vulnerability caused by inappropriate food portion sizes have received considerably less attention within the literature. In situations where consumers feel powerless, this may lead to avoidance and disengagement strategies rather than use of active coping mechanisms (Ben-Zur, 1999; Folkman and Moskowitz, 2004). In the case of inappropriate food portions, this is likely to result in reductions in food intake, thus further contributing to the development of the anorexia of ageing and potentially experiences of consumer vulnerability. Therefore, food consumption practices represent a unique context for exploring consumer vulnerability among older people. While previous studies have examined factors contributing to vulnerability and/or the immediate after effects, few have considered the progressive development of vulnerability. The gradual and progressive nature of ageing and the reduced food intake sometimes associated with later life may provide greater insight into the development of consumer vulnerability, helping to address these limitations with the literature.

\section{Method}

Data collection 
Data was gathered using in-depth semi-structured interviews with older consumers exploring their food consumption practices. Semi-structured interviews were adopted as they allow for probing of views and opinions, offering participants the opportunity to expand their answers and direct the interview into new and potentially insightful pathways (Gray, 2014, p. 383). Semi-structured interviews have also been shown to provide valuable insights in prior studies into consumer vulnerability (e.g. Baker; 2006; Wang and Tian, 2014; Roy and Sanyal, 2017). As such, interviews were considered a suitable approach for providing rich, contextual data into older consumers' experiences with food consumption (Kvale, 2007). During this study, participants were interviewed for an hour to an hour and a half. Interviews took place in the participants' homes. This provided a relaxed atmosphere in which participants were more comfortable to engage with the researchers (Brunk and Blümelhuber, 2011) and allowed participants to refer to specific products during the interviews, thus allowing for the provision of more detailed insights. The interviews began by exploring participants' food shopping habits. Questioning then narrowed to focus on dining habits, and finally specifically examined food consumption experiences. The questions were designed to explore how the multiple dimensions of ageing had impacted not only on food intake, but also the contexts in which food consumption takes place. This is in-line with previous studies which suggest that moments throughout the food consumption process, from purchase to disposal of packaging, can contribute towards consumer vulnerability (Ford et al., 2016). Please send Appendix One for an overview of the interview structure.

\section{Sample}

Based on the exploratory aims of the study, a purposive non-representative sample was adopted. As Masset and Decrop (2015, p. 15) describe, "In qualitative interpretive research, it is not sample representativeness but information richness that matters". Participants were based in the United Kingdom and aged between 60 and 91 years. The lower age bracket was 
adopted as 60 is highlighted in prior studies as the age that many people begin to experience declines in appetite (e.g. Sjögren et al., 1994; NHANES, 1994). The extent to which the sample can be discussed as a homogenous group is limited by the breadth of chronological ages. To alleviate this issue the authors considered patterns in the data between younger and older participants, while also exploring broader themes across the data. The anorexia of ageing is a progressive disorder which is often overlooked or unrecognised within clinical practice (Landi et al., 2016; Cao and Morley, 2016). This means that while a prevalent disorder, not all individuals experience the disorder to the same extent, at the same rate, or at precise/specific times. As a result, the anorexia of ageing is often not formally diagnosed, yet can be somewhat to significantly influential on an individual's food consumption practices. Therefore, the participants were not all diagnosed as suffering from the anorexia of ageing, but the accounts of many revealed experiences of gradual (or in some cases considerable) reductions in food intake befitting of the nature of the anorexia of ageing. In order to offer wider implications for firms, participants living independently within the community were recruited as they reflect the majority of older consumers. Table 1 provides details on each participant. Pseudonyms have been adopted to ensure the anonymity of participants is maintained. 
Insert Table 1 (Participant details) here. 


\section{Data analysis}

With the permission of the participants, all interviews were recorded and subsequently transcribed. Data was analysed in accordance with the guidelines of naturalistic enquiry (Lincoln and Guba, 1985), where the researchers engaged in constant comparison to identify similarities and differences within the data (Charmaz, 2006). An iterative process of reading and re-reading transcripts aided the researchers in establishing patterns and contradictions within the data. Contradictory findings provided avenues for deeper exploration, enhancing theoretical development. Having becoming familiar with the data, the authors analysed transcripts line-by-line to identify initial open codes. Emergent categories were formed. Based on the research aims, the authors started with identifying age-related changes affecting food consumption. Insights relating to levels of food intake were identified, with exploration of how these impacted participants' lives. This included observing feelings of relative control or powerlessness over one's consumption experiences and the implications of this. Following this, categories were classified into themes, summarising the core unifying observations (Goetz and LeCompte, 1981). To enhance the reliability of the analysis, each interview was analysed by all three authors, thus acting as a form of investigator triangulation (Patton, 2002). In so doing, this helped achieve a form of intersubjective certifiability (Sharp and Eddy, 2001), described by Winchester, Hall and Binney (2015) as occurring when more than two authors draw the same conclusions from reviewing the data.

\section{Findings}

The findings illustrate participants' experiences with packaged food products and their perceptions of how ageing has affected their consumption habits. For many, ageing is found to affect shopping habits, dining habits, and food consumption. For a number of participants 
of more advanced ages, their narratives indicate reductions in food intake befitting of the effects of the anorexia of ageing. In some cases, this inhibits the ability to satisfactorily achieve consumption goals where suitable portions of food cannot easily be attained. Among younger participants, the effects of ageing on food consumption practices are less pronounced, reflecting the gradual and heterogeneous nature of the ageing process. Nonetheless, some evidence of generational influence affecting food consumption practices is observable.

The following sub-sections reflect key themes which emerged from the interviews.

\section{Eating less, primary and second ageing}

In-keeping with much of the Gerontological and Nutritional literature, many participants note gradual decreases in appetite as they have aged. For example, Philip attributes significant reductions in his and his wife's food intake to growing older:

"I retired when I was 60, and was still active and well... but this has changed in the past few years. [My appetite] has reduced by around a quarter or half, and even that would be a big meal for us. I think on average my and Elizabeth's appetites have halved" (Philip, 85).

Philip is among several participants to describe what are perceived as 'natural' decreases in appetite due to growing older. A number of participants of varying ages identify such declines in appetite, although these are particularly apparent among older participants within the sample. While some younger participants such as John describe 'very limited' changes to his food consumption as he has grown older, others such as Sally describe the impact of life events on her food requirements: 
“My tastes haven't changed, but my needs have. Since my husband passed away and the kids moved out there isn't a need for so much food anymore" (Sally, 63).

For those experiencing age-related illnesses (secondary ageing), reductions in appetite are often more marked. For example, Bob's narration describes the effects of medication he was prescribed during cancer treatment on his food consumption:

“The pills I was taking were making me ill. It affected taste. I just didn't enjoy eating. My daughter makes a lovely lemon drizzle cake, and I'm a selfish bastard and I don't like anyone else to have it. But with the medicine I just couldn't get the taste. So I gave it to [other daughter]" (Bob, 87).

Bob's experiences support the assertion that changes to an individual's senses in later life may contribute to reduced food intake (Popper and Kroll, 2003; Dean et al., 2009). Food consumption experiences from which he ordinarily derived pleasure became less enjoyable as his senses were inhibited. For those older people with long-term medicinal requirements, extended periods of reduced sensory pleasure from eating may accelerate decreases in food consumption (Doty and Kamath, 2014).

\section{Routinised eating habits}

In addition to biological changes, social ageing also affects food consumption. Several participants, including recent and longstanding retirees, describe how their consumption habits have become more rigidly structured after exiting full-time employment. These changes relate to food shopping, preparation and consumption, including increased regularity of shopping, often in small convenience stores for a small number of specific items. Other notable changes include greater rigidity in meal times. For example, Gerry details his 
consumption schedule:

"Since I retired we have had very set meal times. Breakfast is at 7.30, lunch is at 12 and 5 pm is our dinnertime.... This may vary within half an hour" (Gerry, 83).

This is in-keeping with the findings of Percival (2002) who uncovered the importance of mealtimes towards the management in daily routines in later life. Such routinisation was also described by some younger participants, including recent retiree Norman who details his punctual dining habits, as well as very specific consumption habits:

"I've always been quite an organised person, so now I'm not working I apply that elsewhere in my life. Like with the shopping. I always know what we're eating each day so I always know what to buy each day. This doesn't change” Norman (60).

Norman and Gerry are among several participants to provide insights to suggest that the routinization of daily life following major life transitions, such as entering retirement, may lead to a reduction in dietary variety as regimented shopping habits were found to coincide with the narrowing of food choices. Although reductions in food variety is not directly identified by participants as causes of decreased consumption, over time this reduction in dietary variety may lead to reduced food intake (Marshall et al., 2001; Bhutto and Morley, 2008).

\section{Commensality, expectations and disappointment}

A theme evident in many participants' narratives regarded eating as a social situation. For some, events such as becoming empty nesters meant that commensality featured less in their daily lives, detracting from the level of enjoyment derived from meal times: 
"The children always seemed to be eating. When you are older it's different. With family life you would sit down for dinner and catch up and find out what people have been up to. Meal times were interesting. When you get to our age it's not so interesting" (Barbara, 82).

Barbara's narrative depicts the change in social meaning of meal times to her. Whereas the presence of her children elevated food consumption to a position of great significance and as an opportunity to engage and bond with her family, eating without her children relegates meals to a less enjoyable experience. Being unable to realise the heightened social meaning she attributes to meal times serves as a source of disappointment for Barbara. Conversely, other participants describe how meal times now form a more significant part of their daily lives:

“Meals are much more of an event than when you're young and you're just trying to find the time to have anything... I think it makes me notice more when my food isn't right though... recipes changing, cooking instructions not being right, servings being too much ... stuff like that gets to me more than it used to" (Patricia, 74).

Despite Barbara and Patricia's current feelings appearing somewhat opposing, they both illustrate the importance that meal times can hold in later life. Both wish to partake in consumption experiences that reflect the elevated social meaning which they assign to meal times (Quandt et al., 2000; Paquet et al., 2008). However, age-related changes hinder the enactment and realisation of these experiences. As Patricia alludes to, the greater significance with which she regards meal times also heightens her awareness of problems with packaged food products. Specifically, excessive portion sizes are perceived as detracting from meal times. 


\section{Embarrassment and maintaining independence}

For some, the inability to satisfactorily achieve food consumption goals can lead to feelings of disappointment. For others, the affects can be detrimental in other ways, such as contributing to feelings of incompetence or embarrassment. The latter is evident in Donald's account where he discusses dining with his son:

"If I'm on my own finishing a lot of things is hard work. It puts you in a bit of a negative state of mind... If I go to my son's for lunch I always ask for a kiddie's size meal. It's quite embarrassing... I try not to be an old curmudgeon but these sorts of things make it hard!" (Donald, 88).

Other participants referred to the longer-term negative effects of reduced food consumption:

“Over the years I've eaten less and less. It's a bit depressing really. I haven't got the energy to cook meals but all of the ready-made things are just too much for me. You end up not eating enough and having no energy. Getting out the house and doing normal things gets very hard" (Vivienne, 81).

Discussing her depressive feelings, Vivienne's narrative depicts the immediate negative affect of inappropriate portion sizes. She also describes the detrimental effects to her health and well-being of being unable to achieve her consumption goals. This suggests that longterm experiences of unsuitable portion sizes may detract from older people's psychological well-being, as well as their independence and abilities to maintain social roles (Gabriel and Bowling, 2004). Inappropriate packaged food portions may, therefore, act as a catalyst for subsequent experiences of consumer vulnerability, where changes to an individual's physiology are exacerbated, rendering consumption goals more difficult to achieve. For individuals such as Vivienne for whom the long-term reductions in food intake has negatively 
affected her ability to perform other tasks, these difficulties may lead to feelings of incompetence in certain situations, thus downgrading her self-confidence and damaging her self-concept (Moschis, 1992).

\section{Unwanted reminders of ageing and loneliness}

With packaged foods, unsuitable portion sizes meant that several participants began meals with feelings of frustration. In some cases, these feelings were identified as reminders of negative aspects of the ageing process which directly contribute to reduced consumption:

“As soon as you start cooking, or sometimes even when you're buying it [food products], you realise 'this is just too much for me', you don't feel good... it's another little reminder that you're getting older and you're on your own" (Catherine, 78).

However, for several older participants with significantly reduced appetites, excessive portions and subsequent food wastage elicits more profound emotions that contribute to negative perceptions of the self. For example, Eve regards food wastage as an unwanted symptom of the ageing process:

'I hate having to waste stuff, but sometimes you just can't avoid it. The problem is these days everything is made for families. Most things I buy I know I won't finish. It makes you feel bad, you know? There's nothing you can do about it though, it's one of many irritating things that comes with age" (Eve, 73).

For Eve, reduced food intake due to biological changes has been exacerbated by social changes that mean she now lives alone. Purchasing products that no longer meet her requirements reinforces negative aspects of the ageing process. Being unable to consume the same levels of food as she once did evokes unwanted negative emotions that affect her self- 
concept of age. Eve's lack of control over her consumption experiences as regards portion size comes as "an unwelcome reminder of the frailties of the individual" which may contribute to experiences of consumer vulnerability (Baker et al., 2005, p. 132).

\section{Consumption ethos and food waste}

A recurrent theme in the interviews was an expression of participants' 'waste-not want-not' attitude, often attributed to their war-time/post-war upbringing. Many participants describe feelings of irritation towards packaged food manufacturers who they view as creating barriers to responsible consumption:

"The way me and my siblings were brought up was very much 'waste-not want-not'. I think that stays with you. Having had very little I think you have a bit more of an appreciation for what you've got and don't like anything going to waste. You sometimes feel like you're fighting a losing battle though as everything is so big now [food products]" (Fiona, 65).

For individuals like Fiona, food waste due to inappropriate portion sizes acts as a source of frustration. For others such as Robert (63), similar experiences evoke feelings of guilt due the 'significant environmental damage' he suspects food waste causes, describing how packaged food manufactures are 'stacking the odds against them' regarding socially responsible consumption. For younger participants such as Fiona and Robert, their frustrations with food wastage stem not from notable changes to their appetites, but from their values and perceived generational norms. Likewise, Jane remarks on her frustrations with wasting food, citing her upbringing as shaping her views: 
"You're told to do your bit for the good of the planet, but for the companies there seems to be a disconnect. What good is recycling if you're throwing out food because the packets are so big you can't get through them... It's not the way I was brought up" (Jane, 62).

These insights demonstrate a degree of the heterogeneity of factors affecting food consumption practices. While not attributed to age-related changes, these extracts demonstrate the influence of generational norms, in this case on perceptions of food waste.

\section{Coping practices, blaming portion sizes}

While packaged food portion sizes can pose problems to achieving consumption goals, participants utilise a variety of problem-solving strategies, demonstrating that consumers are not simply passive recipients of vulnerability (Baker et al., 2005). Moschis (2000) suggests that older people experiencing health related stress may focus on regulating emotions since they believe they cannot control their situation. In the case of food consumption, older people may first use behavioural coping strategies to regain control. For example, Bob describes changes to his shopping habits to meet his new requirements:

"I've used the delicatessen for years now as the stuff in packs is too much for me. Me and my wife used them before to get a few slices of ham for lunch. Now she's in a home and it's just me I still use it but just for a slice or two now" (Bob, 87).

Such is the extent of the changes to Bob's appetite that he describes avoiding purchasing prepackaged foods "at all costs", seeking alternatives closer to his requirements wherever possible. Others such as Anne describe utilisation of her freezer as a coping mechanism 
against unsuitable portion sizes. Her narration highlights this approach, but also the dissatisfaction of relying on this mechanism:

"We normally try to buy things that are a suitable portion for our appetites... I was particularly pleased to find a small pizza in Lidl the other day... But when we can't do this we will buy the smallest and then freeze half of it.... its gets very annoying to having to always do this though. You wish you didn't have to." (Anne, 86).

Similarly, Jill describes using her freezer to divide what she considers 'oversized' portions into more suitable sizes, but also expresses discontent towards packaged food manufacturers at needing to employ this approach:

"Sometimes if something's too big I'll freeze it. This is a pain though. I've only got so much space in my freezer and so many tubs to put stuff in! It would be so easier if things were just smaller. I can't be the only one who has this problem?” (Jill, 77).

Using these behavioural coping strategies, participants demonstrate mastery, utilising positive coping mechanisms to empower themselves in response to stresses (Ben-Zur, 2002; Folkman and Moskowitz, 2004). Responses to unsuitable portion sizes are in-line with the concept of planful problem solving, where individuals take direct action to deal with a problem and its effects (Blanchard-Fields et al., 2007). However, the majority of participants convey a sense of dissatisfaction at needing to employ such mechanisms, expressing a preference for food products that they perceive as meeting their needs. Although her freezer provides Kate with a means of self-partitioning portions into more manageable sizes, it also leads a reduction of dietary variety: 
“Where I can I'll freeze stuff. That way I can take a few days to finish something without it going off. It means I end up eating the same stuff a lot though which gets very boring" (Kate, 91).

For some, problem-solving strategies employed in response to inappropriate portion sizes may, therefore, contribute to more monotonous dietary intake (Age UK, 2012). This highlights the opportunity for food marketers to enable more varied food consumption among some older consumers through the provision of smaller food portions. This may, in turn, lead to increased food intake as greater pleasure will be derived from consumption experiences (de Boer et al., 2013).

\section{Smaller portions facilitating increased consumption}

In addition to providing psychological benefits through reduced wastage, our findings also suggest that reduced apportionment may actually increase food intake among older people experiencing the anorexia of ageing. For example, several participants described feelings of being 'overwhelmed' and 'over-faced' by large portion sizes, concluding that their food intake increases when smaller portions are available:

"If there's a smaller version I'll always go for that one. I think I end up eating more if it is a smaller pack. Bigger ones are so overwhelming it just puts you off' (Marilyn, 84).

These findings reflect the assertions of Macht et al. (2002) and de Boer et al. (2013) who suggest that negative moods may lead to decreased food consumption. This is also apparent in other consumption contexts, such as when eating at restaurants: 
"I choose from the child's menu. I find it off-putting when they put a great big plate of food in front of you and you know very well you're not going to bloody eat it all. I'm much happier with the smaller option because I can manage them" (Donald, 88).

Similarly, Eve (73) expressed dissatisfaction towards oversized restaurant portions, describing how she regularly requests 'half-size' portions when ordering to better meet her needs. In a restaurant context, consumers may be more able to employ problem-solving strategies than with packaged food where the ability to 'personalise' products to one's needs is comparatively limited. These insights suggest that rather than leading to decreased consumption, reduced portion sizes may contribute to increased food intake among some older people. For those participants who demonstrate an awareness of reductions in their appetite, the prospect of attempting to consume what they perceive as being overly large portions may lead to less food intake than if presented with a smaller, more 'manageable' portion. This supports the findings of Laidlaw et al. (2002) who describe the negative impact of food wastage on the self-concepts of individuals who adhere to a 'waste-not want-not' mantra. However, our findings suggest that unwanted reminders of negative aspects of the ageing process that food wastage evokes may be as significant a factor in exacerbating the anorexia of ageing, thus contributing to experiences of consumer vulnerability.

\section{Discussion and conclusions}

The anorexia of ageing renders portion sizes of many packaged foods inappropriate for some older people. This creates an imbalance between consumption goals and marketplace offerings, wherein food products featuring smaller portion sizes are sought but are unavailable. In order for this imbalance to be addressed, dependence is often placed on food marketers to create greater fairness in the marketplace. In this case, fairness is represented by 
the availability of smaller food portions. Where smaller, more appropriate products are available, consumption goals can be more easily achieved. Where appropriate products are not available and the achievement of consumption goals is hindered, this can lead to negative ramifications for an individual's self-concept.

Our findings suggest that ageing can impact on food consumption practices in a variety of ways. Among those participants of more advanced ages, feelings of dissatisfaction are often elevated to experiences of consumer vulnerability as food wastage acts an unwelcome reminder of negative aspects of the ageing process, including increased fragility and isolation. Where meal times are attributed with heightened social meaning, the inability to achieve these consumption goals can be particularly damaging to an individual's self-concept. If impeded, consumption goals of any sort can lead to experiences of vulnerability, irrespective of how modest those goals may appear (Baker et al., 2005). This is somewhat in contrast with the experiences of some younger participants for whom unsuitable food portions may act as a source of frustration, but with comparatively innocuous effects in their current life-stage.

Participants' narratives provide insights into the development and experience of incidents of consumer vulnerability. From the data, four key stages of potential vulnerability can be identified: proximate, immediate, intermediate and ultimate (see Table 2). Each stage has potential to elicit feelings of frustration, or in some cases powerlessness befitting of consumer vulnerability. Exploring experiences across the food consumption processes helps to reveal how vulnerability may occur at any stage, not only during or immediately following the consumption of unsuitable portions, but possibly while shopping, preparing food, disposing of or employing coping mechanisms to deal with excess food. These stages capture how inappropriate food portions may contribute to immediate experiences of consumer vulnerability wherein consumers are unable to satisfactorily achieve their consumption goals. Inappropriate food portions can also provide the impetus for future experiences of 
vulnerability by exacerbating the effects of the anorexia of ageing, thus contributing to the biological changes which may result in increased frailty (Martone et al., 2013). The accumulation of incidents of vulnerability over time, including sustained periods of reduced food consumption, may act as a catalyst for increased frailty among older people. This could contribute to subsequent experiences of vulnerability beyond food consumption, thus pervading into other areas of an individual's life. 
Insert Table 2 (Four stages of vulnerability development and experience) here. 
In their conceptualisation of consumer vulnerability, Commuri and Ekici (2008) argue the case for class-based classifications of consumers, wherein populations are segmented based on their susceptibility to experience vulnerability. This is in contrast to the stated-based view of vulnerability where consumers qualify as vulnerable only when vulnerability is experienced or expressed (e.g. Hogg et al., 2007; Adkins and Jae, 2010). Embedded in the latter conceptualisation is the recommendation that firms should avoid explicitly positioning products which may alleviate vulnerability towards specific consumer segments as this may lead to stigma and anxiety. Our findings suggest that through reduced apportionment packaged food firms may be able to provide discreet intervention to facilitate increased food intake among older people, thus potentially reducing experiences of vulnerability. However, questions remain regarding the positioning and commercial viability of such products. Evidence suggests that products positioned explicitly towards older consumers are often rejected as older people do not wish to purchase products which label them as them 'old' (e.g. Moschis et al., 1997; Myers and Lumbers, 2008). Instead, Marketers should position products according to the benefits they offer. In this case, a key benefit being the convenience of smaller portions for those eating individually, regardless of age - for example, the 7.7 million people living alone in the United Kingdom (ONS, 2016).

\section{Theoretical contributions}

Exploring the food consumption practices of older consumers provides a unique contribution to consumer vulnerability literature (e.g. Hamilton et al., 2015) by examining the concept in an underexplored area. The findings presented in this paper provide a developmental perspective on experiences of vulnerability that is not fully captured within other studies. 
This perspective offers a more granular view with which to understand the development and experience of consumer vulnerability. Although previous studies have provided valuable insights into older people's experiences of vulnerability in different contexts, most tend to focus only on the situational factors leading to those experiences and/or the immediate after effects, with the more enduring implications of these experiences afforded less attention. For example, Alves and Wilson's (2008) exploration of factors contributing to susceptibility to telemarketing fraud, or Griffiths and Harmon's (2011) examination of older people's vulnerability when providing informed consent for medical and clinical services. These studies are in keeping with the state-based view of vulnerability, where vulnerability is considered to be transitory. However, the developmental nature of vulnerability caused by reduced food intake can be seen to elicit both impermanent experiences of vulnerability, while also contributing towards longer-term, sustained vulnerability that may pervade into wider-reaching contexts of an individual's life. Therefore, this study provides new insights towards understanding how impermanent state-based experiences of vulnerability may progress into extended periods of vulnerability more befitting of a class-based view. This perspective has the potential to offer more detailed, nuanced insights into vulnerability in other contexts beyond food consumption, aiding researchers in understanding how and why consumer vulnerability occurs.

Our study also provides new knowledge on the food consumption practices of older people, in particular with regards to levels of food intake. While previous studies into food portions address issues of food intake, they do not account for the effects of the ageing process. Our study presents a fundamentally different research problem to those studies investigating methods to reduce food intake. Our findings reveal a counter-intuitive scenario where increased portion sizes may contribute to the onset and exacerbation of the anorexia of ageing. This is in contrast to prior studies that posit that large portion sizes increase 
consumption (e.g. Wansink, 2004; Chandon and Wansink, 2011; Zlatevska et al., 2014). Our findings suggest that food intake may, in fact, increase among older consumers when consuming smaller portions.

\section{Managerial implications}

Our findings highlight the opportunity for food marketers contribute to the maintenance of adequate food consumption in later life. Through suitable apportionment food marketers may be able provide products which offer discreet, low-level support to older consumers in maintaining sufficient level of food consumption and, in turn, contributing to the reduction of future experiences of vulnerability. In several cases, participant's narratives implied or directly stated that smaller portion sizes lead them to consume greater amounts of food. However, acceptance of smaller products in actual shopping contexts is unclear. Vermeer $e t$ al. (2010) warn that reducing product size risks firms being perceived as deceitful and of offering lower value. Further investigation is, therefore, required to establish optimum packaging solutions to communicate the benefits of reduced apportionment whilst not appearing to offer lower value. According to Vermeer et al. (2009), packaged food firms providing a variety of portion sizes will offer consumers the greatest value. However, this is likely to present challenges to retailers providing an already highly fragmented variety of products. In particular, such an approach to product assortment planning may be unfeasible for convenience stores with modest shelf space (Mantrala et al., 2009). This creates a conflicting situation where the types of shops that participants frequented most (e.g. convenience stores) are the least able accommodate a greater variety of products.

Opportunities may be available to firms to offer greater value through reduced apportionment without alienating other consumers by tailoring retail service development to include more 
facilities such as delicatessens which were used as positive-coping mechanisms by some participants. The provision of facilities which allow for individualised apportionment, such as delicatessens, will facilitate increased consumer empowerment. This may help reduce experiences of consumer vulnerability among older people, whilst not disadvantaging other consumers who require larger portion sizes. Consideration will need to be given, however, to the commercial viability of such an approach and the potential impact on retail efficiency and profitability.

\section{Limitations and future research directions}

Further research is required to build upon the insights this study has provided to determine optimum portion sizes and container composition to encourage sufficient food intake among older people. For instance, larger-scale quantitative studies with older people examining behaviour towards various portion sizes and perceptions of alternative packaging would provide more generalizable results. Further research exploring in greater depth older consumers' problem solving strategies and food consumption contexts (e.g. Tan et al., 2015) would also provide a valuable contribution to the current body of knowledge. Studies exploring food consumption of older people across different countries would help to address the limitation of the current study involving only consumers based in the United Kingdom. Prior research suggests differences in both quality-of-life criteria across cultures (e.g. Walker, 2005), as well as variance in the cultural significance of eating (e.g. Wahlqvist et al., 2009; Counihan and Van Esterik, 2013). As such, research across a variety of geographical contexts would aid international firms. 


\section{References}

Adkins, N. R., \& Jae, H. (2010). Marketplace Vulnerability of Limited English Proficient Consumers: Opportunities to increase Knowledge in Marcomarketing. Journal of Macomarketing, 30(1), 93-104. doi:10.1177/0276146709352222

Age UK. (2012). Food Shopping in Later Life. Retrieved September 24, 2012, from http://www.ageuk.org.uk/Documents/EN-GB/Forprofessionals/Conferences/Final_Food_Shopping_Report.pdf?dtrk=true

Ahmad, R. (2002). The older or ageing consumers in the UK: are they really that different? International Journal of Market Research, 44(3), 337-360.

Aldwin, C. M. (1991). Does age affect the stress and coping process? Implications of age differences in perceived control. Journal of Gerontology: Psychological Sciences, 46(4), 174-180.

Alves, L. M., \& Wilson, S. R. (2008). The Effects of Loneliness on Telemarketing Fraud Vulnerability Among Older Adults. Journal of Elder Abuse \& Neglect, 20(1), 63-85. doi:10.1300/J084v20n01_04

Amatulli, C., Guido, G., \& Nataraajan, R. (2015). Luxury purchasing among older consumers: exploring inferences about cognitive Age, status, and style motivations. Journal of Business Research, 68(9), 1945-1952. doi:10.1016/j.jbusres.2015.01.004

Baker, S. M. (2006). Consumer normalcy: Understanding the value of shopping through narratives of consumers with visual impairments. Journal of Retailing, 82(1), 37-50.

Baker, S. M., Gentry, J. W., \& Rittenburg, T. L. (2005). Building Understanding of the Domain of Consumer Vulnerability. Journal of Macromarketing, 25(2), 128-139. doi:10.1177/0276146705280622

Benelam, B. (2009). Satiety and the anorexia of ageing. British Journal of Community Nursing, 14(8), 332-335. doi:10.12968/bjen.2009.14.8.43512

Ben-Zur, H. (1999). The effectiveness of coping meta-strategies: perceived efficiency, emotional correlates, and cognitive performance. Personality and Individual Differences, 26(5), 923-939. 
Ben-Zur, H. (2002). Coping, affect and aging: the role of mastery and self-esteem. Personality and Individual Differences, 32(2), 357-372.

Bhutto, A., \& Morley, J. E. (2008). The clinical significance of gastrointestinal changes with aging. Current Opinion in Clinical Nutrition and Metabolic Care, 11(5), 651-660. doi:10.1097/MCO.0b013e32830b5d37

Blanchard-Fields, F., Mienaltowski, A., \& Seay, R. B. (2007). Age Differences in Everyday Problem-Solving Effectiveness: Older Adults Select More Effective Strategies for Interpersonal Problems. Journal of Gerontology: Psychological Sciences, 62(1), 6164.

Bond, J., Peace, S., Dittmann-Kohli, F., \& Westerhof, G. (2007). Ageing in Society. London: Sage.

Briefel, R. R., McDowell, M. A., Alaimo, K., Caughman, C. R., Bischof, A. L., Carroll, M. D., \& Johnson, C. L. (1995). Total energy intake of the US population: the third National Health and Nutrition Examination Survey, 1988-1991. American Journal of Clinical Nutrition, 62(5), 10725-10805.

Brunk, K. H., \& Blümelhuber, C. (2011). One strike and you're out: Qualitative insights into the formation of consumers' ethical company or brand perceptions. Journal of Business Research, 64(2), 134-141. doi:10.1016/j.jbusres.2010.02.009

Cao, L., \& Morley, J. E. (2016). Sarcopenia is recognized as an independent condition by an international classification of disease, tenth revision, clinical modification (ICD-10CM) code. Journal of the American Medical Directors Association, 17(8), 675-677. doi:10.1016/j.jamda.2016.06.001

Chandon, P., \& Wansink, B. (2011). Is Food Marketing Making Us Fat? A MultiDisciplinary Review. Foundations and Trends in Marketing, 5(3), 113-196. doi:10.1561/1700000016

Charmaz, K. (2006). Constructing Grounded Theory: A Practical Guide Through Qualitative Analysis. London: SAGE Publications Ltd. 
Clarkston, W. K., Pantano, M. M., Morley, J. E., Horowitz, M., Littlefield, J. M., \& Burton, F. R. (1997). Evidence for the anorexia of aging: gastrointestinal transit and hunger in healthy elderly vs. young adults. American Journal of Physiology, 272(1), 243-248.

Commuri, S., \& Ekici, A. (2008). An Enlargement of the Notion of Consumer Vulnerability. Journal of Macromarketing, 28(2), 183-186. doi:10.1177/0276146705280622

Conte, C., Cascino, A., Bartali, B., Donini, L. M., Rossi-Fanelli, F., \& Laviano, A. (2009). Anorexia of Aging. Current Nutrition \& Food Science, 5(1), 9-12. doi:10.2174/157340109787314776

Cornil, Y., \& Chandon, P. (2016). Pleasure as a Substitute for Size: How Multisensory Imagery Can Make People Happier with Smaller Food Portions. Journal of Marketing Research, 53(5), 847-864. doi:10.1509/jmr.14.0299

Counihan, C., \& Van Esterik, E. (Eds.). (2013). Food and Culture. New York: Routledge.

de Boer, A., Ter Horst, G. J., \& Lorist, M. M. (2013). Physiological and psychosocial agerelated changes associated with reduced food intake in older persons. Ageing Research Reviews, 12(1), 316-328. doi:10.1016/j.arr.2012.08.002

Dean, M., Raats, M. M., \& Grunert, K. G. (2009). Older people, food and satisfaction with life. In M. Dean, M. M. Raats, \& K. G. Grunert (Eds.), Food for the ageing population (pp. 3-15). Boca Raton: Woodhead Publishing Limited.

DiPietro, L., Anda, R. F., Williamson, D. F., \& Stunkard, A. J. (1992). Depressive symptoms and weight change in a national cohort of adults. International Journal of Obesity and Related Metabolic Disorders, 16(10), 745-753.

do Vale, R. C., Pieters, R., \& Zeelenberg, M. (2008). Perverse Package Size Effects on Consumption Self-Regulation. Journal of Consumer Research, 35(3), 380-390. doi:10.1086/589564

Donini, L. M., Savina, C., \& Cannella, C. (2003). Eating habits and appetite control in the elderly: the anorexia of aging. International Psychogeriatrics, 15(1), 73-87.

Doty, R. L., \& Kamath, V. (2014). The influences of age on olfaction: a review. Frontiers in Psychology, 5(20), 1-20. doi:10.3389/fpsyg.2014.00020 
Duizer, L. M., Robertson, T., \& Han, J. (2009). Requirements for packaging from an ageing consumer's perspective. Packaging Technology and Science, 22(4), 187-197. doi:10.1002/pts.834

Folkman, S., \& Moskowitz, J. T. (2004). Coping: Pitfalls and Promise. Annual Review of Psychology, 55, 745-774. doi:10.1146/annurev.psych.55.090902.141456

Ford, N., Trott, P., \& Simms, C. (2016). Exploring the impact of packaging interactions on quality of life among older consumers. Journal of Marketing Management, 32(3/4), 275-312. doi:10.1080/0267257X.2015.1123758

Gabriel, Z., \& Bowling, A. (2004). Quality of life from the perspectives of older. Ageing and Society, 24(5), 675-691. doi:10.1017/S0144686X03001582

Goetz, J. P., \& LeCompte, M. D. (1981). Ethnographic Research and the Problem of Data Reduction. Anthropology \& Education Quarterly, 12(1), 51-70.

Gray, D. E. (2014). Doing Research in the Real World. London: SAGE Publications Ltd.

Griffiths, M. A., \& Harmon, T. R. (2011). Aging Consumer Vulnerabilities Influencing Factors of Acquiescence to Informed Consent. The Journal of Consumer Affairs, 45(3), 445-466. doi:10.1111/j.1745-6606.2011.01212.x

Hamilton, K., Dunnett, S., \& Piacentini, M. (Eds.). (2015). Consumer Vulnerability: Conditions, Contexts and Characteristics. Abingdon: Routledge.

Hays, N. P., \& Roberts, S. B. (2006). The anorexia of aging in humans. Physiology \& Behavior, 88(3), 257-266. doi:10.1016/j.physbeh.2006.05.029

Hogg, M. K., Howells, G., \& Milman, D. (2007). Consumers in the Knowledge-Based Economy (KBE): What creates and/or constitutes consumer vulnerability in the KBE? Journal of Consumer Policy, 30(2), 151-158. doi:10.1007/s10603-007-9030-9

Horwitz, B. A., Blanton, C. A., \& McDonald, R. B. (2002). Physiologic determinants of the anorexia of aging: Insights from animal studies. Annual Review of Nutrition, 22, 417438. doi:10.1146/annurev.nutr.22.120301.071049

Koehler, K. M. (1994). The New Mexico Aging Process Study. Nutrition Reviews, 52(8), 3437. doi:10.1111/j.1753-4887.1994.tb01446.x 
Kuppelwieser, V. G., \& Sarstedt, M. (2014). Exploring the influence of customers' time horizon perspectives on the satisfaction-loyalty link. Journal of Business Research, 67(12), 2620-2627. doi:10.1016/j.jbusres.2014.03.021

Kvale, S. (2007). Doing Interviews. London: SAGE Publications Ltd.

Laidlaw, K., Thompson, L. W., Gallagher-Thompson, D., \& Dick-Siskin, L. (2002). Cognitive Behaviour Therapy with Older People. Chichester: John Wiley \& Sons.

Landi, F., Calvani, R., Tosato, M., Martone, A. M., Ortolani, E., Savera, G., . . Marzetti, E. (2016). Anorexia of aging: Risk factors, consequences, and potential treatments. Nutrients, 8(2), 69-79. doi:10.3390/nu8020069

Langenderfer, J., \& Shimp, T. A. (2001). Consumer vulnerability to scams, swindles, and fraud: A new theory of visceral influences on persuasion. Pscyhology \& Marketing, 18(7), 763-783. doi:10.1002/mar.1029

Lee, J., \& Geistfeld, L. V. (1999). Elderly Consumers' Receptiveness to Telemarketing Fraud. Journal of Public Policy \& Marketing, 18(2), 208-217.

Lee, J., \& Soberon-Ferrer, H. (1997). Consumer Vulnerability to Fraud: Influencing Factors. Journal of Consumer Affairs, 31(1), 70-89. doi:10.1111/j.1745-6606.1997.tb00827.x

Leventhal, R. C. (1997). Aging consumers and their effects on the marketplace. Journal of Consumer Marketing, 14(4), 276-281.

Lincoln, Y. S., \& Guba, E. G. (1985). Naturalistic Inquiry. London: Sage.

Macht, M., Roth, S., \& Ellgring, H. (2002). Chocolate eating in healthy men during experimentally induced sadness and joy. Appetite, 39(2), 147-158. doi:10.1006/appe.2002.0499

MacIntosh, C., Morley, J. E., \& Chapman, I. M. (2000). The Anorexia of Aging. Nutrition, 16(10), 983-995. doi:10.1016/S0899-9007(00)00405-6

Malafarina, V., Uriz-Otano, F., Gil-Guerrero, L., \& Iniesta, R. (2013). The anorexia of ageing: Physiopathology, prevalence, associated comorbidity and mortality. A systematic review. Maturitas, 74(4), 293-302. doi:10.1016/j.maturitas.2013.01.016 
Mantrala, K. M., Levy, M., Kahn, B. E., Fox, E. J., Gaidarev, P., Dankworth, B., \& Shah, D. (2009). Why is Assortment Planning so Difficult for Retailers? A Framework and Research Agenda. Journal of Retailing, 85(1), 71-83. doi:10.1016/j.jretai.2008.11.006

Marshall, T. A., Stumbo, P. J., Warren, J. J., \& Xie, X.-J. (2001). Inadequate Nutrient Intakes Are Common and Are Associated with Low Diet Variety in Rural, CommunityDwelling Elderly. Journal of Nutrition, 131(8), 2192-2196.

Martone, A. M., Onder, G., Vetrano, D. L., Ortolani, E., Tosato, M., Marzetti, E., \& Landi, F. (2013). Anorexia of Aging: A Modifiable Risk Factor for Frailty. Nutrients, 5(10), 4126-4133. doi:10.3390/nu5104126

Masoro, E. J. (2006). Are Age-Associated Diseases an Integral Part of Aging? In E. J. Masoro, \& S. N. Austad (Eds.), Handbook of the Biology of Aging (pp. 43-62). Burlington, MA: Elsevier.

Masset, J., \& Decrop, A. (2015). “God, I have so many ashtrays!” Dependences and dependencies in. Journal of Business Research, In press. doi:10.1016/j.jbusres.2015.07.024

Mathey, M. F., Vanneste, V. G., de Graaf, C., de Groot, L. C., \& van Staveren, W. A. (2001). Health effect of improved meal ambiance in a Dutch nursing home: a 1-year intervention study. Preventive Medicine, 32(5), 416-423. doi:10.1006/pmed.2001.0816

McKay-Nesbitt, J., Manchanda, R. V., Smith, M. C., \& Huhmann, B. A. (2011). Effects of age, need for cognition, and affective intensity on advertising effectiveness. Journal of Business Research, 64(1), 12-17. doi:10.1016/j.jbusres.2009.09.013

McKie, L. (1999). Older people and food: independence, locality and diet. British Food Journal, 101(7), 528-536. doi:10.1108/00070709910279036

Morley, J. E. (1997). Anorexia of aging: physiologic and pathalogic. American Journal of Clinical Nutrition, 66(4), 760-773.

Morley, J. E., Anker, S. D., \& Evans, W. J. (2009). Cachexia and aging: An update based on the fourth international cachexia meeting. Journal of Nutrition, Health and Aging, 13(1), 47-55. 
Moschis, G. P. (1992). Marketing to Older Consumers: A Handbook of Information for Strategy Development. Westport: Quorum Books.

Moschis, G. P. (2000). Consumer behavior in later life: Multidisciplinary approaches and methodological issues. Research in Consumer Behavior, 9, 103-128.

Moschis, G. P., Lee, E., \& Mathur, A. (1997). Targeting the mature market: opportunities and challenges. Journal of Consumer Marketing, 14(4), 283-293.

Moschis, G. P., Mosteller, J., \& Fatt, C. K. (2011). Research Frontiers on Older Consumers' Vulnerability. Journal of Consumer Affairs, 45(3), 467-491.

Myers, H., \& Lumbers, M. (2008). Understanding older shoppers: a phenomenological investigation. Journal of Consumer Marketing, 25(5), 294-301.

NHANES. (1994). National Health and Nutrition Examination Survey - Daily dietary fat and total food intake. Morbidity and Mortality Weekly Report, 43, 116-125.

ONS. (2016). Office for National Statistics. Retrieved from Families and households in the UK: 2016:

https://www.ons.gov.uk/peoplepopulationandcommunity/birthsdeathsandmarriages/fa milies/bulletins/familiesandhouseholds/2016

Paquet, C., St.-Arnaud-McKenzie, D., Ma, Z., Kergoat, M.-J., Ferland, G., \& Dubé, L. (2008). More Than Just not Being Alone: The Number, Nature, and Complementarity of Meal-Time Social Interactions Influence Food Intake in Hospitalized Elderly Patients. The Gerontologist, 48(5), 603-611. doi:10.1093/geront/48.5.603

Patton, M. Q. (2002). Qualitative Research and Evaluation Methods. California: Thousand Oaks.

Percival, J. (2002). Domestic spaces: uses and meanings in the daily lives of older people. Ageing and Society, 22(6), 729-749. doi:10.1017/S0144686X02008917

Popper, R., \& Kroll, B. (2003). Food preference and consumption among the elderly. Food Technology, 57(7), 32-40. 
Quandt, S. A., McDonald, J., Arcury, T. A., Bell, R. A., \& Vitolins, M. Z. (2000). Nutritional self-management of elderly widows in rural communities. Gerontologist, 40(1), 8696. doi:10.1093/geront/40.1.86

Raats, M., de Groot, L., \& van Staveren, W. (Eds.). (2009). Food for the ageing population. Boca Raton: CRC Press.

Roy, S., \& Sanyal, S. N. (2017). Perceived consumption vulnerability of elderly citizens: a qualitative exploration of the construct and its consequences. Qualitative Market Research: An International Journal,, Just-accepted. doi:10.1108/QMR-11-2016-0113

Sharp, A., \& Eddy, C. (2001). Softly, softly catch the monkey: innovative approaches to measure socially sensitive and complex issues in evaluation researc. The Canadian Journal of Program Evaluation, 16(2), 87-99.

Shultz II, C. J., \& Holbrook, M. B. (2009). The Paradoxical Relationships Between Marketing and Vulnerability. Journal of Public Policy \& Marketing, 28(1), 124-127. doi:10.1509/jppm.28.1.124

Sjögren, A., Österberg, T., \& Steen, B. (1994). Intake of Energy, Nutrients and Food Items in a Ten-year Cohort Comparison and in a Six-year Longitudinal Perspective: A Population Study of 70- and 76-year-old Swedish People. Age and Ageing, 23(2), 108-112. doi:10.1093/ageing/23.2.108

Soenen, S., \& Chapman, I. M. (2013). Body Weight, Anorexia, and Undernutrition in Older People. Journal of the American Medical Directors Association, 14(9), 642-648. doi:10.1016/j.jamda.2013.02.004

Sudbury-Riley, L. (2014). Unwrapping Senior Consumers' Packaging Experiences. Marketing Intelligence and Planning, 32(6), 666-686.

Szmigin, I., \& Carrigan, M. (2010). The Older Consumers as Innovator: Does Cognitive Age Hold the Key? Journal of Marketing Management, 16(5), 505-527.

Tan, M. C., Dubelaar, C., \& Zlatevska, N. (2015). The Effects of Social Setting and Portion Sizes on Food Consumption Amount. Asia-Pacific Advances in Consumer Research, (p. 264). 
United Nations. (2017). World Population Prospects: Key findings \& advance tables. Department of Economic and Social Affairs, Population Division: United Nations.

Vermeer, W. M., Alting, E., Steenhuis, I. H., \& Seidell, J. C. (2010). Value for money or making the healthy choice: the impact of proportional pricing on consumers' portion size choices. (65-69, Ed.) The European Journal of Public Health, 20(1). doi:10.1093/eurpub/ckp092

Vermeer, W. M., Steenhuis, I. H., \& Seidell, J. C. (2009). From the point-of-purchase perspective: A qualitative study of the feasibility of interventions aimed at portionsize. Health Policy, 90(1), 73-80. doi:10.1016/j.healthpol.2008.07.006

Wahlqvist, M. L., Lee, M. S., \& Kouris-Blazor, A. (2009). Demographic and cultural differences in older people's food choices and meal patterns. In M. Raats, L. de Groot, $\&$ W. van Staveren (Eds.), Food for the ageing population (pp. 20-42). Boca Raton: CRC Press.

Walker, A. (Ed.). (2005). Growing Older in Europe. Maidenhead: Open University Press.

Wang, J. J., \& Tian, Q. (2014). Consumer Vulnerability and Marketplace Exclusion: A Case of Rural Migrants and Financial Services in China. Journal of Macromarketing, 34(1), 45-56. doi:10.1177/0276146713508137

Wansink, B. (1996). Can package size accelerate usage volume? Journal of Marketing, 60(3), $1-14$.

Wansink, B. (2004). Environmental factors that increase the food intake and consumption volume of unknowing consumers. Annual Review of Nutrition, 24, 455-479. doi:10.1146/annurev.nutr.24.012003.132140

Winchester, T., Hall, J., \& Binney, W. (2015). Evaluating young adult voter decision-making involvement within a compulsory political system. Qualitative Market Research: An International Journal, 18(3), 252-277. doi:10.1108/QMR-09-2013-0061

Yoxall, A., Langley, J., Musslewhite, C., Rodriguez-Falcon, E. M., \& Rowson, J. (2010). Husband, Daughter, Son and Postman, Hot-water, Knife and Towel: Assistive Strategies for Jar Opening. In P. M. Langdon, P. J. Clarkson, \& P. Robinson (Eds.), Designing Inclusive Interactions (pp. 187-196). London: Springer. 
Zlatevska, N., Dubelaar, C., \& Holden, S. S. (2014). Sizing Up the Effect of Portion Size on Consumption: A Meta-Analytic Review. Journal of Marketing, 78(3), 140-154. doi:10.1509/jm.12.0303

\section{Appendix One: Interview Template}

Food shopping habits/routines

1. Where and how often do you shop for packaged food products?

a. How do you travel to the shop?

b. Do you should alone or with others?

2. Have your food shopping habits changed in recent years?

a. If so, please describe these changes.

Dining habits

1. Please describe your dining habits on a 'typical' day.

2. Do you eat alone or with others?

a. Has this changed?

3. Have your dining habits changed in recent years?

a. If so, what has led to these changes?

\section{$\underline{\text { Food consumption }}$}

1. Is food preparation and consumption important to you?

2. Has the amount of food you consume changed in recent years?

a. If so, please describe these changes.

b. What do you think has led to these changes?

c. When did you first notice these changes?

d. If food consumption has reduced, how does this make you feel?

3. Do most of the food products you purchase come in suitable portions?

a. If not, how do this make you feel?

b. If not, how do you manage this difference in portion provision and requirement? 